\title{
Is there a specific stage to rest? Morphological changes in flower primordia in relation to endodormancy
}

\section{in sweet cherry (Prunus avium L.)}

\author{
Erica Fadón ${ }^{1-2}$, Javier Rodrigo ${ }^{1}$, and Maria Herrero ${ }^{2}$ \\ ${ }^{1}$ Centro de Investigación y Tecnología Agroalimentaria de Aragón. Instituto Agroalimentario de Aragón - IA2 \\ (CITA-Universidad de Zaragoza), Av. Montañana 930, 50059 Zaragoza, Spain \\ ${ }^{2}$ Estación Experimental Aula Dei, CSIC, Av. Montañana 1005, 50059 Zaragoza, Spain \\ ORCID: ${ }^{1} 0000-0002-8321-1764 ;{ }^{2} 0000-0002-3499-1602$;
}

Corresponding autor: jrodrigo@aragon.es, +34 976716314

\begin{abstract}
In temperate woody deciduous perennials, dormancy is a survival strategy to persist winter temperatures; but chilling is also required for the release of flower bud dormancy and for the completion of flower development. This was noticed over hundred years ago, but the biological mechanisms underlying cold regulated dormancy and its release remain poorly understood. That chilling is required for the completion of flower development led us to hypothesize that a particular stage of flower development may be consistently associated with the dormant phase of flower bud development. Flower development of five sweet cherry cultivars was examined weekly under stereoscopic and optical microscopes over three years. Chilling requirements for each cultivar were determined by placing weekly shoots in forcing conditions. The establishment of a flower developmental scale showed that early and late flower development, in the autumn and spring, were asynchronous among cultivars and years. However, in all circumstances, dormancy occurred at the same stage of flower development, characterized by the presence of all flower whorls, with the anthers clearly differentiated in the four locules, and the pistil showing an incipient ovary, style and stigma. The length of time flower buds remained at this stage differed between cultivars and was related to their chilling requirements and date of flowering. The observation that a particular stage of flower development, common to the five cultivars examined, exists during the combined rest period provides a framework for further studies on the physiology and cellular biology of dormancy.
\end{abstract}

\section{Key Words}

Chilling requirements; flower development; Prunus avium; sweet cherry; winter dormancy.

\section{Key message}

Comparison of five sweet cherry cultivars - over three years - shows an asynchronous early and late flower development, but a consistent, specific flower developmental stage for dormancy.

Conflict of interest The authors declare that they have no conflict of interest. 


\section{INTRODUCTION}

Temperate woody deciduous perennials adapt to the seasons by modulating their growth and development (Cooke et al. 2012) and they survive winter temperatures by entering a dormant stage (Perry 1971). This is a survival strategy; but in addition to promoting flower bud dormancy, it has been long known that cold winter temperatures are required for dormancy enter and release and for the completion of flower development (Knight 1801; Coville 1920). The requirement of duration and depth of dormancy are genetically determined and are correlated with the accumulated exposure to chilling temperatures. Thus, temperate zone fruit trees need a genotype-specific amount of chilling for the flower buds to develop and flower normally (Jansson and Douglas 2007; Castède et al. 2014). However, the biological mechanisms underlying cold regulated dormancy and its release remain poorly understood.

Recently, there has been a search for genes that may be involved in the regulation of dormancy in woody perennials (Fadón et al. 2015a; Liu et al. 2015; Sanchez Martín-Fontecha et al. 2017; Tarancon et al. 2017; Fadón and Rodrigo 2018). While metabolic cell cycle arrest accompanies dormancy (Velappan et al. 2017), some physiological processes seem to continue during midwinter, such as starch accumulation (Felker et al. 1983; Fadón et al. 2018) and changes in other carbohydrates (Kaufmann and Blanke 2017; Beauvieux et al. 2018). The enlargement of nuclei and nucleoli (Thompson 1996), plasma membrane and cell wall modificacions (Beauvieux et al. 2018) and changes in phytohormone concentration, including auxins, cytokinins, and abscisic acid (ABA) have also been related to dormancy (Vanstraelen and Benková 2012; Ionescu et al. 2017). In addition, water status and dehydrins have been associated with dormancy and acclimatization to freezing (Rinne et al. 2010; Malagi et al. 2015; Kaufmann and Blanke 2017). However, the information available remains fragmented and it is difficult to frame the results of the genetic and physiological control of dormancy. One of the main drawback is the lack of consensus to determinate the dormancy status (Dennis 2003; Campoy et al. 2011; Fadón and Rodrigo 2018). In an attempt to understand dormancy, a terminology was developed for temperate fruit trees. Thus, the regulation by physiological factors inside the affected structure is referred to as endodormancy, and the term ecodormancy refers to dormancy regulated by environmental factors (Lang et al.1987). Other terms have been coined concerning dormancy in different species and the subject has recently been comprehensively reviewed (Considine and Considine 2016).

Although dormancy can be studied from different approaches, the dormancy status is usually determined by the analyses of vegetative or flower buds (Fadón and Rodrigo 2018). However, relatively little attention has been given to the flower primordia inside the buds. Flower development provides an excellent opportunity for 
frame dormancy studies (Julian et al. 2014), as it is a consistent process with very conserved, clear milestones, as characterized in herbaceous model species (Koltunow et al. 1990; Smyth et al. 1990; Brukhin et al. 2003). Unfortunately, these species do not display dormancy; however, the characterization of flower development in temperate trees will provide an opportunity to relate these two parameters. That chilling is required for the completion of flower development led us to hypothesize that a particular stage of flower development may be consistently associated with the dormant phase of flower bud development.

Fruit trees provide an excellent opportunity to test this this stage-contingent dormancy hypothesis; their clonal origin assures consistent genetic differences between cultivars and allows this hypothesis to be tested in different cultivars over different years. Prunus species bloom in late winter or early spring, but their flower buds develop over several months, with flower initiation occurring at the end of the previous summer (Kurokura et al. 2013). Previous studies on floral development have focused attention on floral induction (Tufts and Morrow 1925; Diaz et al. 1981; Guimond et al. 1998; Lamp et al. 2001), early flower development (Brown and Kotob 1957; Felker et al. 1983; Luna et al. 1991; Reinoso et al. 2002; Yamane et al. 2006), bud burst (Kuhn 2006; Pacini et al. 1986; Julian et al. 2010), and the progamic phase at flowering (Rodrigo et al. 2000; Hedhly et al. 2007). Although there is some information available that relates to the stage at which Prunus flowers become dormant, these data are somewhat scarce and inconsistent.

The objective of this study is to determine if there is a specific developmental stage required for dormancy in sweet cherry (Prunus avium L.). For this purpose, flower development was followed from dormancy induction to anthesis in five cultivars, with different flowering dates and chilling requirements, over three years. The determination of chilling requirements for each cultivar provided a basis to relate flower development and dormancy. The results lead us to establish a developmental scale for flower primordia and to characterize a consistent, specific flower development stage required for dormancy.

\section{MATERIALS AND METHODS}

\section{Plant material}

Five sweet cherry cultivars were selected according to their blooming date: Cristobalina (extra-early), Earlise (early), Bing and Burlat (medium), and Skeena (late) (Gella et al. 2001). Three trees per cultivar were used from a cultivar collection located at "Centro de Investigación y Tecnología Agroalimentaria de Aragón" (CITA) in Zaragoza (Spain) at $41^{\circ} 44^{\prime} 30^{\prime \prime} \mathrm{N}, 0^{\circ} 47^{\prime} 00^{\prime \prime} \mathrm{W}$ and $220 \mathrm{~m}$ above sea level. The 20 -year-old trees were grafted on Santa Lucia 64 rootstock (Prunus mahaleb). 


\section{Determination of breaking of endodormancy}

To estimate the date at which endodormancy was broken, two or three year-old branches were sampled starting in the autumn, on the $30^{\text {th }}$ November, until the onset of budbreak, at the end of February or early March. Each week, three branches $(15-30 \mathrm{~cm}$ in length and $5 \mathrm{~mm}$ in diameter) containing at least ten flower buds, were collected at random from each cultivar. Branches were placed on water-soaked florist foam and maintained in a growth chamber at $22 \pm 1{ }^{\circ} \mathrm{C}$ with a 12-hour light photoperiod. For a reference point, at the same time, ten flower buds were randomly picked in the field and individually weighed.

After a week in the growth chamber, ten flower buds per cultivar were randomly picked from the branches and individually weighed. The date of breaking of endodormancy was established when the weight of the flower buds after a week in the growth chamber increased by at least $30 \%$ over the buds weighed directly from the field (Brown and Kotob 1957).

\section{Estimation of chilling and heat requirements}

The temperature was recorded hourly at a meteorological station located in the experimental orchard. Winter temperatures varied over the three years, with a very mild autumn during the second year that resulted in significantly higher minimum temperatures in November and December than in the other two years (Fig. 1). Winter chilling accumulation was calculated for the five cultivars according the "Utah Model. This model proposes the sum of "chill-units" (CU), which establish a different chilling contribution for different temperature ranges (Richardson et al. 1975). Chilling was recorded from the beginning of the autumn, on the first of October. Chill-units were calculated until the end of endodormancy for each cultivar, establishing the specific chilling-units required for each cultivar. Heat accumulation was measured using the Growing Degree Hours (GDH) model (Richardson et al. 1974).

\section{Flower bud growth and characterization of flower development}

Another set of ten flower buds per cultivar and per sampling date were collected at random and individually weighed. Flower buds were sampled on spurs, where most of the flower buds in sweet cherry trees are located (Herrero et al. 2017). Sampling was carried out over three years, from the end of the summer until flowering time for each cultivar. Sampling was done weekly until early spring, when it was implemented every two days.

For the characterization of flower development, three out of the ten flower buds collected per cultivar and sampling date, each bud containing about three or four flower primordia, were dissected and examined under 
a binocular microscope and photographed with a DC-300 digital camera (Leica, Cambridge, UK). A numerical flower developmental scale was developed, in order to examine flower development in relation to time and temperature.

\section{Microscope preparations}

During the first year, two flower buds from each sampling day were fixed in ethanol, acetic acid (3:1), overnight. Flower buds were embedded in Historesin (Leica, Heidelberg, Germany) and sectioned at $5 \mu \mathrm{m}$ following the protocol of Losada and Herrero (2012). The sections were stained for DNA with a solution of $0.25 \mathrm{mg} / \mathrm{mL}$ of 4 ',6-diamidino-2-phenylindole (DAPI) (Williams et al. 1999) or with 0.05 M DAPI, and 0.0035\% Calcofluor for cellulose (Hughes and McCully 1975) at a ratio of 1:6; over five minutes. Preparations were observed under a UV epifluorescence DM2500 microscope with a 340-380 bandpass and 425 longpass filter. Micrographs were taken with a Leica DFC-310 digital camera with the Leica Application Suites Version 4.2.0 software (Leica Microsystems, Cambridge, UK).

\section{Statistical analyses}

Statistical analyses were performed with SPSS 23 software (SPSS Inc., Chicago, IL, USA). One-way ANOVA was performed to analyze the duration (number of days) of the flower stage during dormancy among cultivars and years. Pearson's chi-square test of independence for categorical variables was used to analyze the stage of flower development between cultivars for each collecting day. When Pearson's chi-square test of independence generated significant differences $(\mathrm{P}<0.05)$, percentage separations were determined by chi-square tests of independence in contingency tables with Yates' correction for continuity. In those cases where expected cell frequencies were low, Fisher's exact test was implemented.

\section{RESULTS}

\section{Flower bud growth and chilling requirements}

The dates of chilling fulfilment were highly variable between cultivars, ranging from the third week of December for 'Cristobalina' to the first week of February for 'Skeena' (Fig. 2). The dates of chilling fulfilment allowed estimation of the chilling requirements of each cultivar. 'Cristobalina' was the cultivar with lowest chilling requirements $(687 \pm 94 \mathrm{CU})$, followed by 'Earlise' and 'Burlat' that showed the same chilling 
requirements $(981 \pm 83 \mathrm{CU})$, then 'Bing' $(1082 \pm 27 \mathrm{CU})$, and 'Skeena', which had the highest chilling requirements $(1559 \pm 63 \mathrm{CU})$.

From the end of the autumn and during the winter, all flower buds were at phenological stage 50 in the BBCH scale (Fadón et al. 2015b), when the flower buds are closed and covered by dark brown scales. No external phenological changes were observed until bud burst in early spring. At the end of the summer, the average flower bud weight was around $0.04 \mathrm{~g}$ in all cultivars and years, and was maintained without significant variation throughout dormancy, as it is shown in the colder (year 1) and milder winter (year 2) (Fig. 3). The pattern of growth in year 3 (data not shown) was consistent with year 2.

Chilling fulfillment, which would correspond with the end of endodormancy (Fig. 2), was not associated with any change of bud weight under field conditions, but occurred before flower bud weight increased with a lag of time of 4-5 weeks between both events (Fig. 3). The increase in weight was concomitant with budburst and the change from the external phenological stage 50 to 51 in the $\mathrm{BBCH}$ scale, which is characterized by inflorescence buds swelling, where the flower buds are closed, but light brown scales are visible (Fadón et al. 2015b). This phase from chilling fulfilment to early bud burst would correspond with ecodormancy.

\section{Flower developmental stages}

Each flower bud hosted an inflorescence with up to four flower primordia. In order to characterize flower development and compare different cultivars and years, ten flower development stages were established, covering the flower development process from meristem differentiation to blooming. The first four developmental stages occurred during autumn and winter (Fig. 4), while the six subsequent stages occurred on growth resumption, following bud burst in the spring (Fig. 5).

Stage 1. Sepal primordia are differentiated in a pentagonal whorl (Fig. 4a).

Stage 2. All floral whorls are distinguishable with the pistil still open (Fig 4b, 4c)

Stage 3. All floral whorls are clearly differentiated and the pistil is closed (Fig. 4d, 4e).

Stage 4. Pistil is differentiated, showing an incipient ovary, style and stigma, and the anthers are translucent green (Fig. 4f, 4g).

Stage 5. Flower primordia are growing and the stigma shows incipient papillae (Fig. 5a, 5b).

Stage 6. Petals are pale white and anthers show a bright yellow color (Fig. 5c, 5d).

Stage 7. Petals protrude over the sepals, and the stigma protrudes over the anthers (Fig. 5e, 5f).

Stage 8. Stamen filament is elongated, and the anthers are level with the stigma (Fig. $5 \mathrm{~g}, 5 \mathrm{~h}$ ). 
Stage 9. Balloon stage with anthers located at different heights (Fig. 5i, 5j).

Stage 10. Open flower. Petals spread out and sepals bend (Fig. 5k, 5l).

\section{Flower development in relation to temperature}

Flower development followed a similar pattern in the different cultivars and years studied, with two growth periods (Fig. 6). Early flower development in the autumn was not synchronized, showing significant differences between cultivars. However, all cultivars in all years halted development during endodormancy at stage 4, which lasted significantly longer than the other stages. This stage was reached at different times depending on the cultivar, but was generally attained by the second half of November. After endodormancy, flower resumed rapid growth and development for around four-six weeks, until full bloom (Fig. 6). This period was similar in length in the different cultivars, but the length of stage 4 was significantly different for each cultivar $(\mathrm{P}<0.01)$.

Flower development followed a pattern parallel to GDH accumulation (Fig. 6). There were also two main periods of GDH accumulation, during autumn and spring, while GDH remained almost unchanged with few variations during winter. In the mild winter (the second year), although GDH accumulated slightly during the endodormancy period, no visual signs of flower bud development were observed. Following endodormancy, rapid flower development took place in all cultivars and years, which corresponded with an increase in heat accumulation.

Different winter chilling accumulation conditions were recorded during the three years studied (Fig. 7). Chilling temperatures started to accumulate about 20 days earlier in the coldest winter (the first year) than in the years 2 and 3, resulting in a 20-25 day difference between the years in the theoretical chilling fulfilment for each cultivar. Thus, e.g. 'Cristobalina' (extra-early flowering) fulfilled its chilling requirements about the $14^{\text {th }}$ of December in year 1 , the $28^{\text {th }}$ of December in year 2 and the $30^{\text {th }}$ of December in year 3 , whereas Skeena (late flowering) fulfilled its chilling requirements in $11^{\text {th }}$ of February in year $1,13^{\text {th }}$ of March in year 2 and $27^{\text {th }}$ of February in year 3. In spite of the differences observed between cultivars and years, in all cases the date of chilling fulfilment, which marked the end of endodormancy, occurred when the flower primordia were at developmental stage 4 (Fig. 7). The buds also remained at this stage during ecodormancy during a variable period. Depending on the cultivar and year, Stage 4 lasted for varying lengths of time, being shorter in extraearly flowering cultivar Cristobalina than in the other cultivars until the transition from stage 4 to 5 that marked 
the end of ecodormancy. Each cultivar entered and exited stage 4 at a different photoperiod, but the data were not consistent over years (Fig. 7).

\section{Anther and pistil characterization at the dormant stage}

As flower developmental stage 4 occurred consistently during dormancy among all the different cultivars and years, we decided to further characterize this stage. In the pistil, the stigma papillae had not developed, but the epidermis and stigmatoid tissue were distinguishable (Fig. 8a). In the style, the transmitting and cortical tissues were apparent. The transmitting tissue showed small, elongated cells with a central nucleus, while the cortical tissue contained larger, rounded cells with a laterally placed nucleus (Fig. 8b). The vascular procambium was present as a group of narrow and elongated cells, but without vessel differentiation (Fig. 8b). In the ovary, the locule was apparent (Fig. 8c), but there was no sign of the ovule primordia. The anther locules were differentiated, with the connective and the prevascular tissue visible at the filament insertion area (Fig. 8d). In the anther locule, the sporogenous tissue and tapetum differentiated in an anther locule (Fig. 8e). The different anther layers were already differentiated showing the sporogenous tissue, tapetum, endothelium, middle layers, and epidermis (Fig. 8f).

\section{DISCUSSION}

While the pattern of flower development was conserved along the seasons, there were differences among the cultivars and years, both during autumn and at bud burst. However, a particular stage of flower development consistently occurred at dormancy under all circumstances.

\section{A flower development scale for dormancy studies}

The flower developmental stages described here cover the process from early flower differentiation to blooming, framing it along the seasons. Early stages are consistent with previous studies of floral initiation assessed in different Rosaceous fruit tree species, where flower differentiation takes place after the cessation of vegetative development and prior to leaf abscission (Felker et al. 1983; Reinoso et al. 2002; Foster et al. 2003), and flower development is halted during dormancy (Kurokura et al. 2013; Saito et al. 2015). Subsequent flower development followed a similar pattern to other model species such as Arabidopsis thaliana (Smyth et al. 1990), tobacco (Nicotiana tabacum) (Koltunow et al. 1990), or tomato (Lycopersicon esculentum) (Brukhin et al. 2003). Flower development scales in these non-dormant herbaceous model species identify the same 
stages of development, providing a developmental comparative context for future genetic studies. However, while only 16 days are required for flower differentiation in Arabidopsis (Smyth et al. 1990), in sweet cherry approximately 8 months elapsed between the onset of flower differentiation and flowering (Fadón et al. 2015b). This is consistent with previous reports in woody perennials, where flower differentiation takes place after cessation of vegetative development and prior to leaf abscission (Tufts and Morrow 1925), and flower development is halted during dormancy (Rohde and Bhalerao 2007; Kurokura et al. 2013). In spite of these timing differences, the flower development scale characterized here provides a framework for dormancy studies.

The external phenology of sweet cherry (Fadón et al. 2015b), and the weight of the flower buds have been the standard parameters used to determine the breaking of endodormancy in controlled conditions (Brown and Kotob 1957; Richardson et al. 1974). Our results show that, while in natural conditions these parameters offer little information on flower bud development in relation to dormancy, since no weight changes occurred along endodormancy and ecodormancy, in controlled conditions clear differences were found between cultivars. This raises the question as to whether all cultivars follow the same developmental timing.

\section{Asynchronous early and late flower development}

While the pattern of flower development was highly conserved, the timing of the start and endpoints of the different developmental stages varied between cultivars prior to, during, and following dormancy. These phases occurred while photoperiods and temperatures were decreasing, which in Prunus spp. have been related to a slowdown in bud development regulated by a pronounced photoperiod/temperature interaction (Heide 2008; Kurokura et al. 2013, Cueto et al. 2017). As autumn progressed and flower development slowed down, the differences between the cultivars became attenuated until growth arrest, which occurred consistently, under all circumstances, at the same flower developmental stage. The differences observed here suggest a tight genotype/environment interaction.

Differences also occurred in the timing of flower bud burst between cultivars and years resulted in bud growth restarting earlier when chilling requirements were fulfilled earlier. A similar situation has been reported in apricot, where the initiation of meiosis in the anther varies between years and closely follows the fulfilment of chilling requirements (Julian et al. 2014).

The duration of stage 4 varied depending on the cultivar and the year. Thus, cultivars that presented early bud burst, such as Cristobalina, entered endodormancy later and fulfilled their chilling requirements before, 
displaying a shorter stage 4. This is consistent with works carried out on cultivars with different blooming dates in different Prunus species. Thus, earlier blooming Japanese apricot (Prunus mume L.) cultivars, with low chilling requirements, also entered endodormancy later (Sasaki et al. 2011), whereas earlier blooming almond (Prunus dulcis Miller D.A. Webb) cultivars broke endodormancy before (Del Cueto et al. 2017).

\section{A consistent flower developmental stage for dormancy}

In spite of the different times of entering dormancy and wakening up at bud burst, dormancy consistently occurred in all cultivars and years at the very same stage of development, characterized by the presence of all flower whorls, with the anthers showing the four locules clearly differentiated, and the pistil showing an incipient ovary, style and stigma. The question remains as to whether this flower developmental stage at dormancy is conserved across species. Differentiated flower whorls before dormancy have been reported in other Prunus species (Felker et al. 1983; Julian et al. 2011), while a continuous anatomical development has been observed during late autumn and winter dormancy in peach (Reinoso et al. 2002). This highlights the importance of integrating floral development in dormancy studies. The developmental stage required for endodormancy described here closely corresponds to stage 9 described in Arabidopsis (Smyth et al. 1990). Interestingly, when examining the duration of each stage in this annual species, in which flower development is not halted by dormancy, this stage lasted the longest. Further work is needed to clarify what is happening during this stage.

The fulfilment of chilling requirements — marking the end of endodormancy — occurred in all circumstances when flowers remained at this dormant stage 4. However, morphological changes did not immediately follow the theoretical fulfilment of chilling, and flower buds remained at this stage during ecodormancy. This is consistent with the idea that ecodormancy occurs until environmental conditions are suitable for further growth (Lang et al. 1987). Our results clearly show that the duration of the rest stage is further reflected by differences in blooming date, with the late blooming cultivars remaining longer in this stage.

Taken together, these results provide a flower developmental scale parallel to those of model species and show that a consistent stage of flower development was associated with dormancy, which could help for a better understanding of the biological basis of dormancy. 
Author contribution statement EF, JR and MH conceived and designed the work. EF did the experiments. All authors analyzed and interpreted the data, discussed the results, and helped prepare the final manuscript.

Acknowledgments This work was supported by the Ministerio de Economía y Competitividad — European Regional Development Fund, European Union [grant numbers AGL2012-40239, BES- 2010-037992 to E. F.]; Instituto Nacional de Investigación y Tecnología Agraria y Alimentaria [grant numbers RFP2015-00015-00, RTA2014-00085-00, RTA2017-00003-00]; and Gobierno de Aragón — European Social Fund, European Union [Grupo Consolidado A12_17R].

\section{REFERENCES}

Beauvieux R, Wenden B, Dirlewanger E (2018) Bud dormancy in perennial fruit tree species : a pivotal role for oxidative cues. Front Plant Sci 9:1-13. doi: 10.3389/fpls.2018.00657

Brown DS, Kotob FA (1957) Growth of flower buds of apricot, peach, and pear during the rest period. Proc Am Soc Hortic Sci 69:158-164.

Brukhin V, Hernould M, Gonzalez N, Chevalier C (2003) Flower development schedule in tomato Lycopersicon esculentum cv. sweet cherry. Sex Plant Reprod 15:311-320. https://doi.org/10.1007/s00497-003-0167-7

Campoy JA, Ruiz D, Egea J (2011) Dormancy in temperate fruit trees in a global warming context: a review. Sci Hortic (Amsterdam) 130:357-372. doi: 10.1016/j.scienta.2011.07.011

Castède S, Campoy JA, García JQ, et al (2014) Genetic determinism of phenological traits highly affected by climate change in Prunus avium: flowering date dissected into chilling and heat requirements. New Phytol 202:703-715. doi: 10.1111/nph.12658

Considine MJ, Considine JA (2016) On the language and physiology of dormancy and quiescence in plants. J Exp Bot 67:3189-3203. https://doi.org/10.1093/jxb/erw138

Cooke JEK, Eriksson ME, Junttila O (2012) The dynamic nature of bud dormancy in trees: environmental control and molecular mechanisms. Plant Cell Environ 35:1707-28. https://doi.org/10.1111/j.13653040.2012.02552.x

Coville F V. (1920) The influence of cold in stimulating the growth of plants. Proc Natl Acad Sci 6:434-735. https://doi.org/10.1073/pnas.6.7.434

Del Cueto J, Ionescu IA, Pičmanová M, et al (2017) Cyanogenic glucosides and derivatives in almond and sweet cherry flower buds from dormancy to flowering. Front Plant Sci 8:1-16. doi: 10.3389/fpls.2017.00800

Dennis FG (2003) Problems in standardizing methods for evaluating the chilling requirements for the breaking of dormancy in buds of woody plants. HortScience 38:347-350.

Diaz DH, Rasmussen HP, Dennis FG (1981) Scanning electron microscope examination of flower bud differentiation in sour cherry. J Am Soc Hortic Sci 4:513-515.

Fadón E, Herrero M, Rodrigo J (2015a) Flower bud dormancy in Prunus species. In: Anderson J V. (ed) Advances in plant dormancy. Springer, Switzerland, pp 123-135 
Fadón E, Herrero M, Rodrigo J (2015b) Flower development in sweet cherry framed in the BBCH scale. Sci Hortic (Amsterdam) 192:141-147. https://doi.org/10.1016/j.scienta.2015.05.027

Fadón E, Herrero M, Rodrigo J (2018) Dormant flower buds actively accumulate starch over winter in sweet cherry. Front Plant Sci. https://doi.org/10.3389/fpls.2018.00171

Fadón E, Rodrigo J (2018) Unveiling winter dormancy through empirical experiments. Environ Exp Bot 152:28-36. https://doi.org/10.1016/j.envexpbot.2017.11.006

Felker FC, Robitaille HA, Hess FD (1983) Morphological and ultrastructural development and starch accumulation during chilling of sour cherry flower buds. Am J Bot 70:376-386.

Foster T, Johnston R, Seleznyova A (2003) A morphological and quantitative characterization of early floral development in apple (Malus x domestica Borkh.). Ann Bot 92:199-206. https://doi.org/10.1093/aob/mcg120

Gella R, Fustero R, Rodrigo J (2001) Variedades de cerezo (CD). Diputación General de Aragón, Zaragoza

Gibson PJ, Diggle PK (1997) Structural analysis of female and hermaphroditic flowers of a gynodioecious tree, Ocotea tenera (Laureaceae). Am J Bot 84:298-307.

Guimond CM, Andrews PK, Lang GA (1998) Scanning electron microscopy of floral initiation in sweet cherry. J Am Soc Hortic Sci 123:509-512.

Hedhly A, Hormaza JI, Herrero M (2007) Warm temperatures at bloom reduce fruit set in sweet cherry. J Appl Bot Food Qual 81:158-164.

Heide OM (2008) Interaction of photoperiod and temperature in the control of growth and dormancy of Prunus species. Sci Hortic (Amsterdam) 115:309-314. https://doi.org/10.1016/j.scienta.2007.10.005

Herrero M, Rodrigo J, Wunsch A (2017) Flowering, fruit set and development. In: Quero-Garcia J, Iezzoni A, Lang G, Pulawska J (eds) Cherries: botany, production and uses. CAB International, Boston, pp 1435

Hughes J, McCully ME (1975) The use of an optical brightener in the study of plant structures. Stain Technol 50:319-329.

Ionescu IA, López-Ortega G, Burow M, et al (2017) Transcriptome and metabolite changes during hydrogen cyanamide-induced floral bud break in sweet cherry. Front Plant Sci 8:1-17. doi: $10.3389 /$ fpls.2017.01233

Jansson S, Douglas CJ (2007) Populus: a model system for plant biology. Annu Rev Plant Biol 58:435-58. https://doi.org/10.1146/annurev.arplant.58.032806.103956

Julian C, Herrero M, Rodrigo J (2014) Anther meiosis time is related to winter cold temperatures in apricot (Prunus armeniaca L.). Environ Exp Bot 100:20-25. https://doi.org/10.1016/j.envexpbot.2013.12.002

Julian C, Herrero M, Rodrigo J (2010) Flower bud differentiation and development in fruiting and nonfruiting shoots in relation to fruit set in apricot (Prunus armeniaca L.). Trees 24:833-841. https://doi.org/10.1007/s00468-010-0453-6

Julian C, Rodrigo J, Herrero M (2011) Stamen development and winter dormancy in apricot (Prunus armeniaca). Ann Bot 108:617-25. https://doi.org/10.1093/aob/mcr056

Kaufmann H, Blanke M (2017) Changes in carbohydrate levels and relative water content (RWC) to distinguish dormancy phases in sweet cherry. J Plant Physiol 218:1-5. https://doi.org/10.1016/j.jplph.2017.07.004

Knight TA (1801) Account of some experiments on the ascent of the sap in trees. Philos Trans R Soc London 91:333-353. https://doi.org/10.1098/rstl.1801.0017 
Koltunow a. M, Truettner J, Cox KH, et al (1990) Different temporal and spatial gene expression patterns occur during anther development. Plant Cell 2:1201-1224. https://doi.org/10.1105/tpc.2.12.1201

Kuhn BF (2006) Determination of starch in ovules of the sour cherry cv. "Stevnsbaer.” Eur J Hortic Sci $71: 120-124$.

Kurokura T, Mimida N, Battey NH, Hytönen T (2013) The regulation of seasonal flowering in the Rosaceae. J Exp Bot 64:4131-41. https://doi.org/10.1093/jxb/ert233

Lamp BM, Connell JH, Duncan RA, et al (2001) Almond flower development: floral initiation and organogenesis. J Am Soc Hortic Sci 126:689-696.

Lang GA, Early JD, Martin GC, Darnell RL (1987) Endodormancy, paradormancy, and ecodormancy Physiological terminology and classification for dormancy research. HortScience 22:371-377.

Liu Z, Zhu H, Abbott A (2015) Dormancy behaviors and underlying regulatory mechanisms: from perspective of pathways to epigenetic regulation. In: Advances in plant dormancy. pp 35-47.

Losada JM, Herrero M (2012) Arabinogalactan-protein secretion is associated with the acquisition of stigmatic receptivity in the apple flower. Ann Bot 110:573-84. https://doi.org/10.1093/aob/mcs116

Luna V, Reinoso H, Lorenzo E, et al (1991) Dormancy in peach (Prunus persica L.) flower buds. II. Comparative morphology and phenology in floral and vegetative buds, and the effect of chilling and gibberellin A3. Trees 5:244-246.

Malagi G, Sachet MR, Citadin I, et al (2015) The comparison of dormancy dynamics in apple trees grown under temperate and mild winter climates imposes a renewal of classical approaches. Trees 29:13651380. https://doi.org/10.1007/s00468-015-1214-3

Pacini E, Bellani LM, Lozzi R (1986) Pollen, tapetum and anther development in two cultivars of sweet cherry (Prunus avium). Phytomorphology 36:197-210.

Perry TO (1971) Dormancy of trees in winter. Science 171:29-36. https://doi.org/10.1126/science.171.3966.29

Reinoso H, Luna V, Pharis RP, Bottini R (2002) Dormancy in peach (Prunus persica) flower buds. V. Anatomy of bud development in relation to phenological stage. Can J Bot 80:656-663. https://doi.org/10.1139/b02-052

Richardson EA, Seeley SD, Walker DR (1974) A model for estimating the completion of rest for "Redhaven" and "Elberta" peach trees. HortScience 9:331-332.

Richardson EA, Seeley SD, Walker DR, et al (1975) Pheno-climatography of spring peach bud development. HortScience 10:236-237.

Rinne PLH, Welling A, van der Schoot C (2010) Perennial life style of Populus: dormancy cycling and overwintering. In: Jansson S, Bhalerao R, Groover A (eds) Genetics and genomics of Populus. Springer New York, New York, NY, pp 171-200

Rodrigo J, Hormaza JI, Herrero M (2000) Ovary starch reserves and flower development in apricot (Prunus armeniaca). Physiol Plant 108:35-41. https://doi.org/10.1034/j.1399-3054.2000.108001035.x

Rohde A, Bhalerao RP (2007) Plant dormancy in the perennial context. Trends Plant Sci 12:217-23. https://doi.org/10.1016/j.tplants.2007.03.012

Ruttink T, Arend M, Morreel K, et al (2007) A molecular timetable for apical bud formation and dormancy induction in poplar. Plant Cell Online 19:2370-2390. https://doi.org/10.1105/tpc.107.052811

Saito T, Tuan P a., Katsumi-Horigane A, et al (2015) Development of flower buds in the Japanese pear (Pyrus pyrifolia) from late autumn to early spring. Tree Physiol 35:653-662. 
https://doi.org/10.1093/treephys/tpv043

Sánchez Martín-Fontecha E, Tarancón C, Cubas P (2018) To grow or not to grow, a power-saving program induced in dormant buds. Curr Opin Plant Biol 41:102-109. https://doi.org/10.1016/j.pbi.2017.10.001

Sasaki R, Yamane H, Ooka T, et al (2011) Functional and expressional analyses of PmDAM genes associated with endodormancy in Japanese apricot. Plant Physiol 157:485-97.

Smyth DR, Bowman JL, Meyerowitz EM (1990) Early flower development in Arabidopsis. Plant Cell 2:755-767. https://doi.org/10.1105/tpc.2.8.755

Tarancón C, González-Grandío E, Oliveros JC, et al (2017) A conserved carbon starvation response underlies Bud dormancy in woody and herbaceous species. Front Plant Sci 8:1-21. https://doi.org/10.3389/fpls.2017.00788

Thompson M (1996) Flowering, pollination and fruit set. In: Webster A, Looney N (eds) Cherries: crop physiology, production and uses. Wallingford, pp 223-241

Tufts WP, Morrow EB (1925) Fruit bud differentiation in deciduous fruits. Hilgardia 1:1-14.

Vanstraelen M, Benková E (2012) Hormonal interactions in the regulation of plant development. Annu Rev Cell Dev Biol 28:463-87. https://doi.org/10.1146/annurev-cellbio-101011-155741

Velappan Y, Signorelli S, Considine MJ (2017) Cell cycle arrest in plants: What distinguishes quiescence, dormancy and differentiated G1? Ann Bot 120:495-509. https://doi.org/10.1093/aob/mcx082

Williams JHW, Friedman WEF, Arnold MLA (1999) Developmental selection within the angiosperm style: Using gamete DNA to visualize interspecific pollen competition. Proc Natl Acad Sci 96:9201-9206.

Yamane H, Kashiwa Y, Kakehi E, et al (2006) Differential expression of dehydrin in flower buds of two Japanese apricot cultivars requiring different chilling requirements for bud break. Tree Physiol 26:1559-63.

\section{FIGURE CAPTIONS}

Fig. 1 Temperatures over the three years of experiments. Daily air temperatures (black lines) surrounded by a grey area indicating the daily minimum and maximum temperatures. (a) Year 1, (b) Year 2 (c) Year 3

Fig. 2 Estimation of breaking of dormancy in five sweet cherry cultivars. Flower bud weight $(n=10$; mean \pm standard error) in orchard conditions and after a week in the growth chamber.

Fig. 3 Flower bud growth from autumn to bud burst in five sweet cherry cultivars during a cold and a mild winter. Flower bud weight $(\mathrm{n}=10 ;$ mean \pm standard error $)$ during two years with different winter conditions: Year 1 (cold winter) and Year 2 (mild winter). The pattern of growth in year 3 (data not shown) is consistent with year 2. (a) Cristobalina, (b) Earlise, (c) Burlat, (d) Bing and (e) Skeena 
Fig. 4 Flower developmental stages from differentiation until dormancy in the sweet cherry. (a) Stage 1: flower primordia differentiation with five sepal primordia in a pentagonal whorl. Several flower primordia gather in a flower bud and flower size differs among flowers of the same bud. (b) Stage 2: three flower primordia gather in a flower bud, with the sepal primordia curved inward. (c) Stage 2: early differentiation of the flower whorls: sepals, petals, stamens and a semi-circular pistil. (d) Stage 3: four flower primordia gather in a flower bud, with the sepal primordia slightly translucent covering each flower primordium. (e) Stage 3: anthers show their characteristic shape and the pistil forms the suture line (arrow). Flowers from the same bud show the same developmental stage. (f) Stage 4: four flower primordia gather in a flower bud, each covered completely by greenish sepal primordia. (g) Stage 4: The anthers have a translucent green appearance, with the four locules clearly differentiated. In the pistil, an incipient ovary, style and stigma are apparent. (a, c, e, g) Scale bars=200 $\mu \mathrm{m}$. (b, d, f) Scale bars $=500 \mu \mathrm{m}$. an: anther, fp: flower primordia, ov: incipient ovary, pe: petal, pi: pistil, se: sepal, stg: incipient stigma, sty: incipient style.

Fig. 5 Flower developmental stages from bud burst to bloom in the sweet cherry. (a) Stage 5: three flower primordia completely green swelling. (b) Stage 5: the flower primordia increase in size and the stigmatic papillae start developing. (c) Three flower primordia separated gather in a flower bud (d) Stage 6: petals turn a pale white colour and the anthers turn bright yellow. (e) Stage 7: a single flower with the white tip of the petals appearing on top. (f) Stage 7: petals surpass the sepals and the pistil surpasses the anthers. (g) Stage 8: a single flower with the sepals starting to separate. (h) Stage 8: the stamen filaments elongate and the anthers reach the level of stigma. (i) Stage 9: a single flower with the petals forming a balloon and sepals completely opened (j) Stage 9: The style has reached its final length and the anthers are located at different heights. (k) Stage 10: Open flower, with the petals spread out and the sepals bend (1) Stage 10: open flower, with the anthers dehisced and the stigma receptive. (a, b, d) Scale bars $=1 \mathrm{~mm}$. (c, e, f, g, h, i, j, k, l) Scale bars=2 mm. an: anther, ov: ovary; pe: petal, se: sepal, ss: stigma, st: style

Fig. 6 Flower developmental stages and Growing Degree Hours (GDH) accumulation in five sweet cherry cultivars from flower differentiation to blooming over three years. (a) Year 1 (b), Year 2, (c) Year 3. Within a collecting day, $\mathrm{n}=3$, ns indicates no significant differences between cultivars, and * indicates significant differences at $\mathrm{P}<0.05$ using contingency tables followed by chi-square tests of independence with Yates' correction for continuity or the Fisher's exact test as appropriate 
Fig. 7 Duration of the flower developmental stage 4 in relation to chilling accumulation and photoperiod in five sweet cherry cultivars over three years. (a) Year 1 (b), Year 2, (c) Year 3. Horizontal grey bars corresponding to each cultivar show the length of stage 4 in each year. Continuous lines correspond to the accumulation of Chilling Units (CU) (left y-axis), in which the snowflake (1) shows the date of chilling fulfilment for each cultivar, and the dotted line corresponds to the photoperiod (right y-axis).

Fig. 8 Pistil and anther tissues during dormancy (stage 4). (a) Stigma with papillae still undifferentiated but stigmatoid tissue distinguishable. (b) Style with cortical and transmitting tissue differentiated. (c) Ovary locule apparent, but ovule primordium still undifferentiated. (d) Anther locules differentiated and prevascular tissue at the filament insertion area. (e) Sporogenous tissue and tapetum differentiated in an anther locule. (f) Anther wall layers differentiated. transmitting tissue (tt), cortical tissue (ct), ovary locule (ol), anther locule (al), vascular procambium (vp), sporogenous tissue (sp), tapetum (ta), epidermis (ep), middle layers (ml). (a-c, e, f) Stained with $0.25 \mathrm{mg} / \mathrm{mL}$ of DAPI; (d) Stained with a solution of $0.05 \mathrm{M}$ DAPI, and $0.0035 \%$ Calcofluor at a ratio of $1: 6$. Scale bars $=20 \mu \mathrm{m}$ 


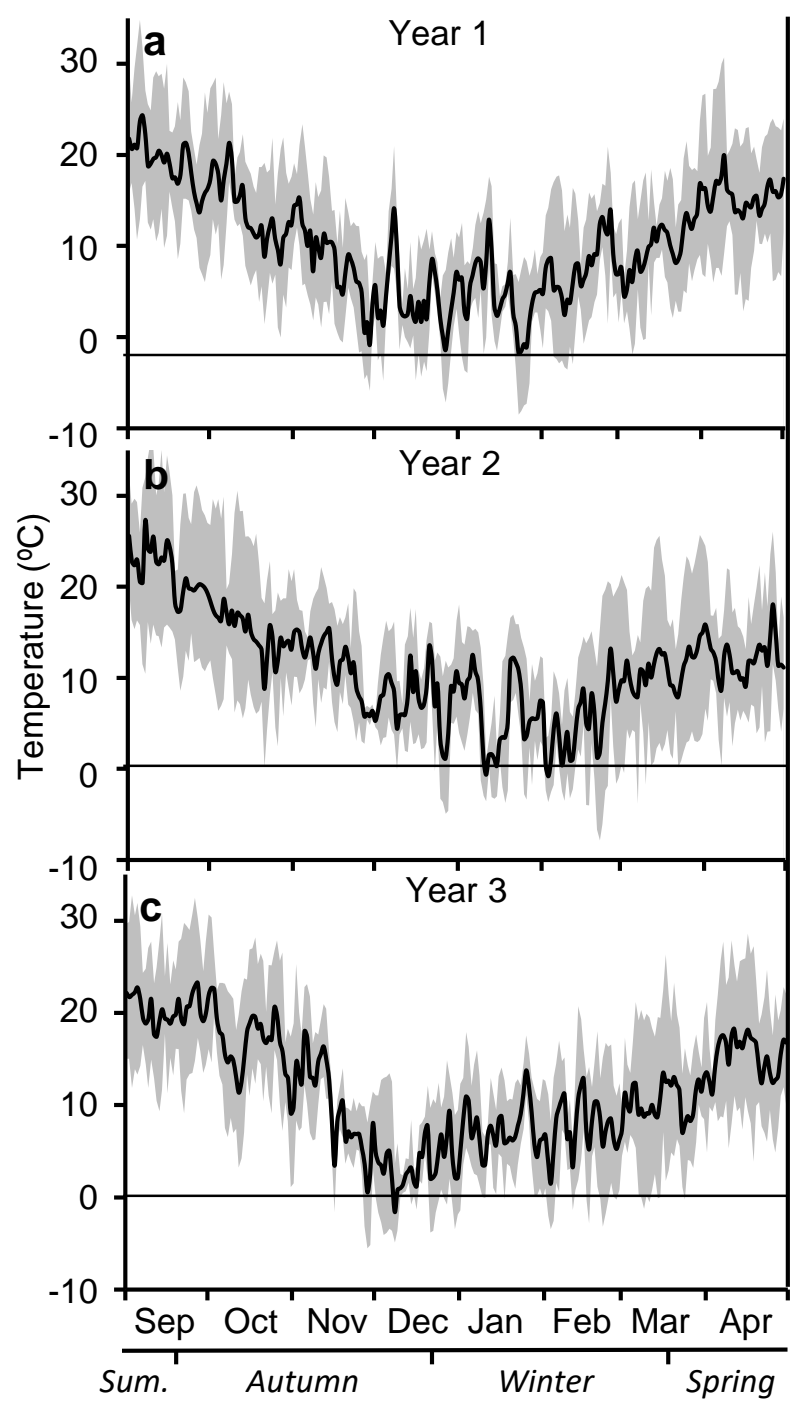




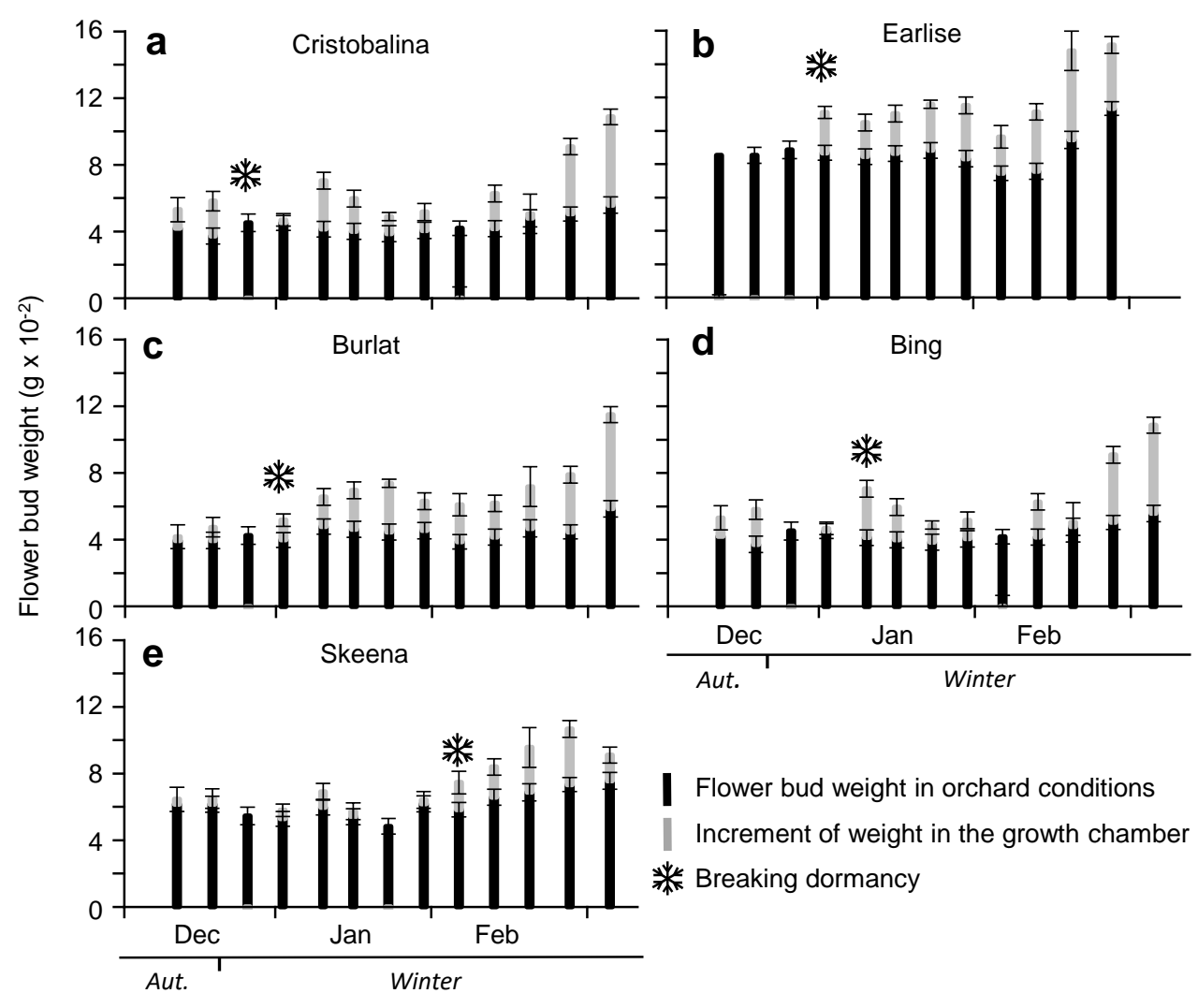




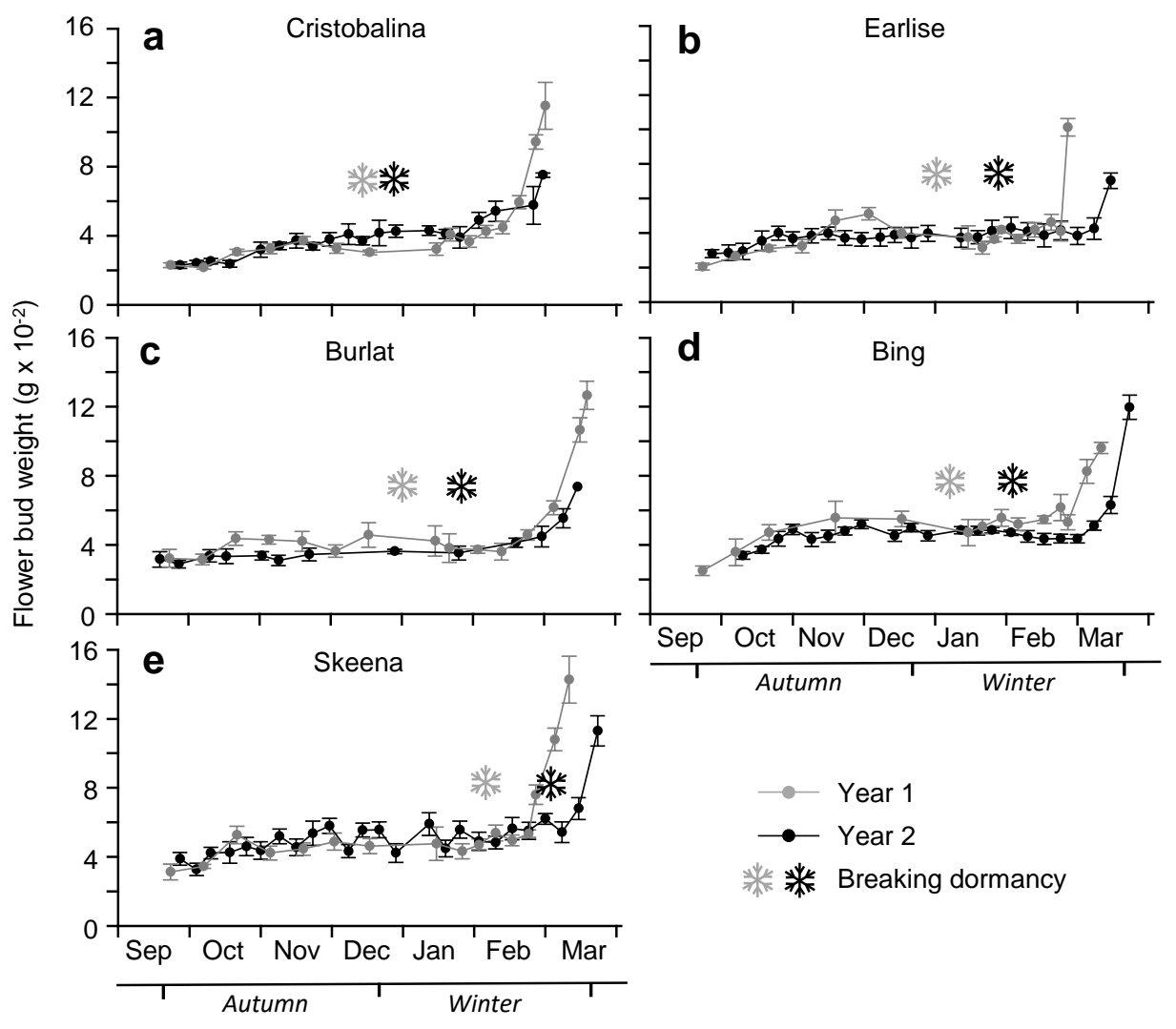


a

Stage 1 b

c

Stage 2

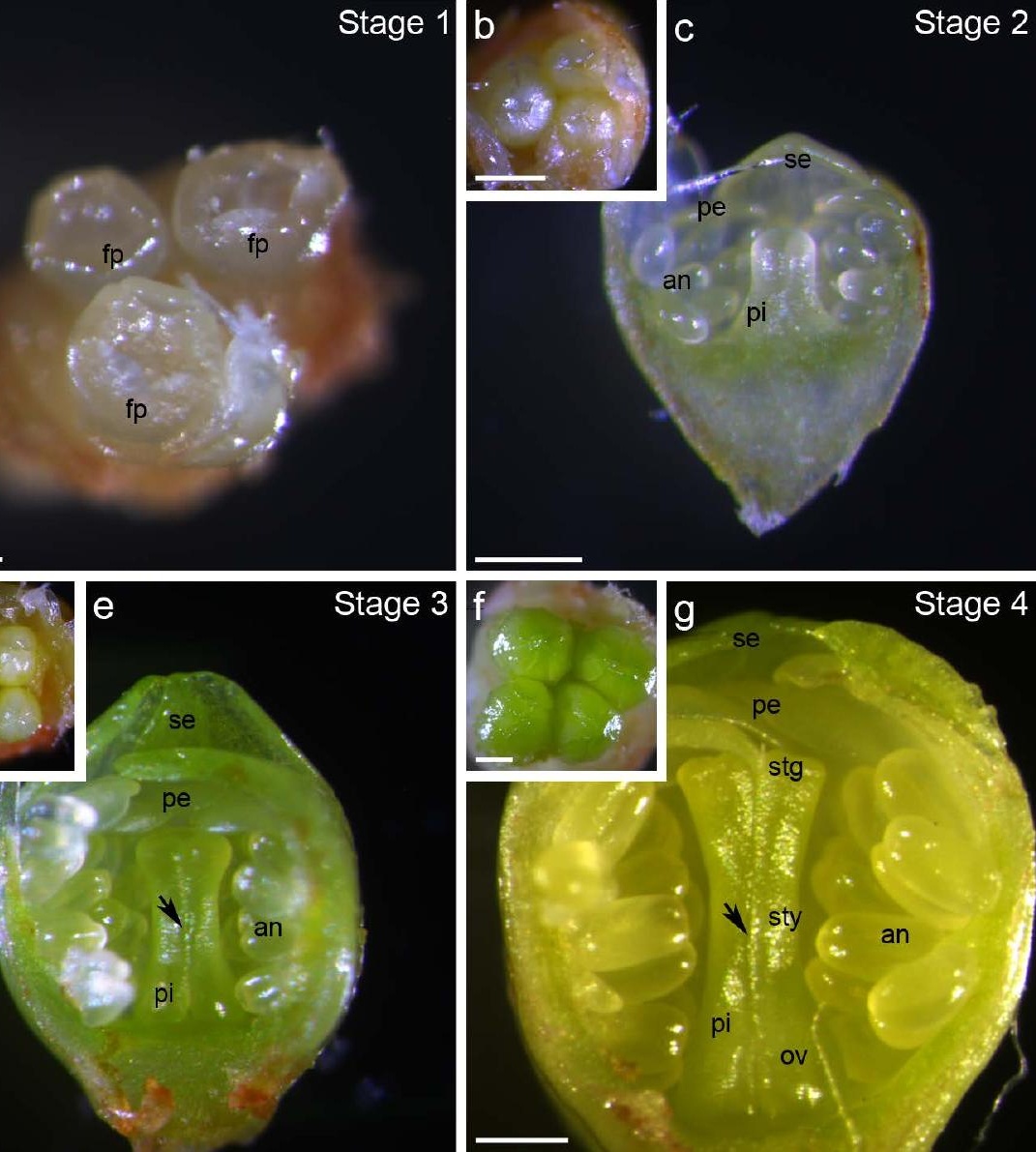




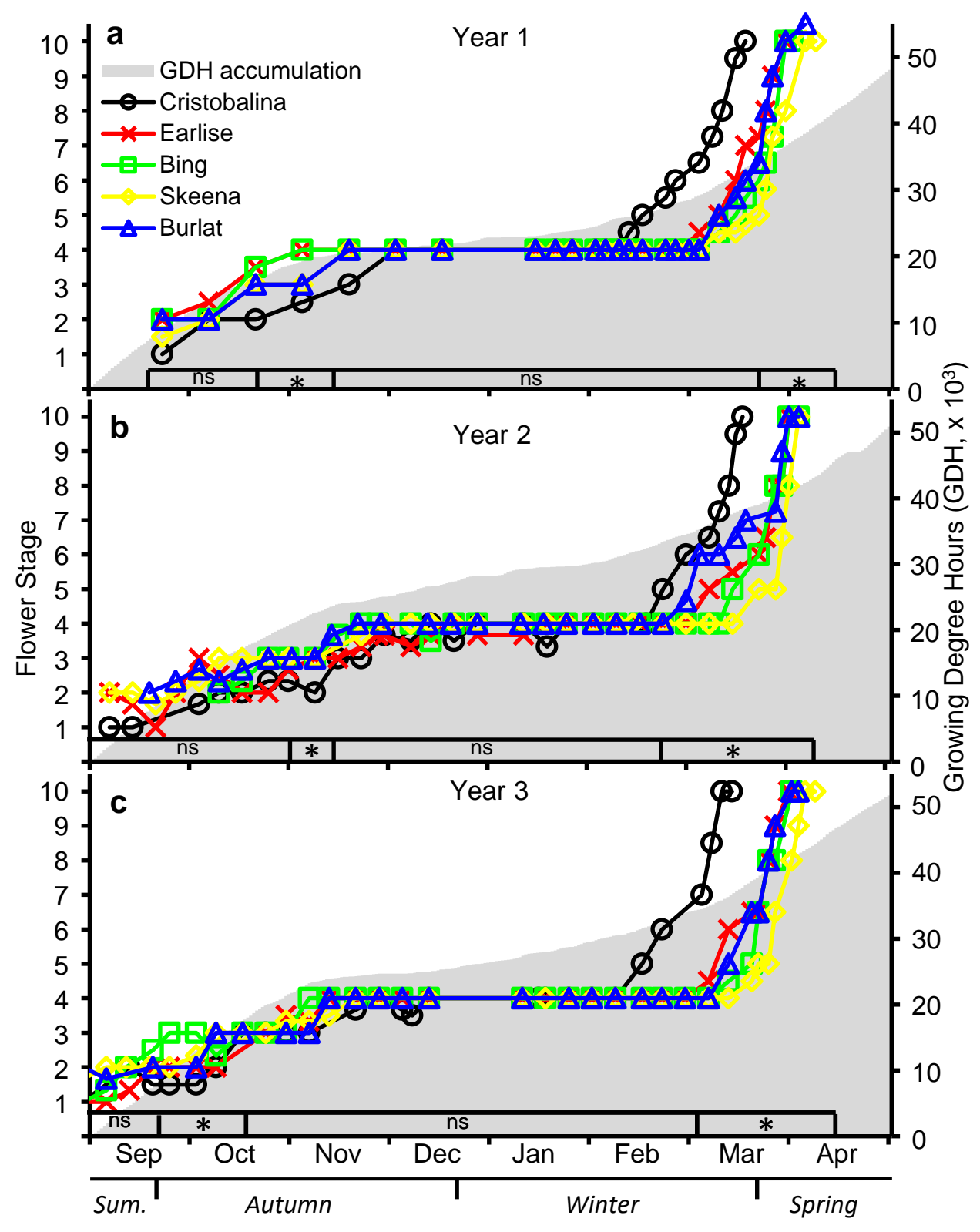




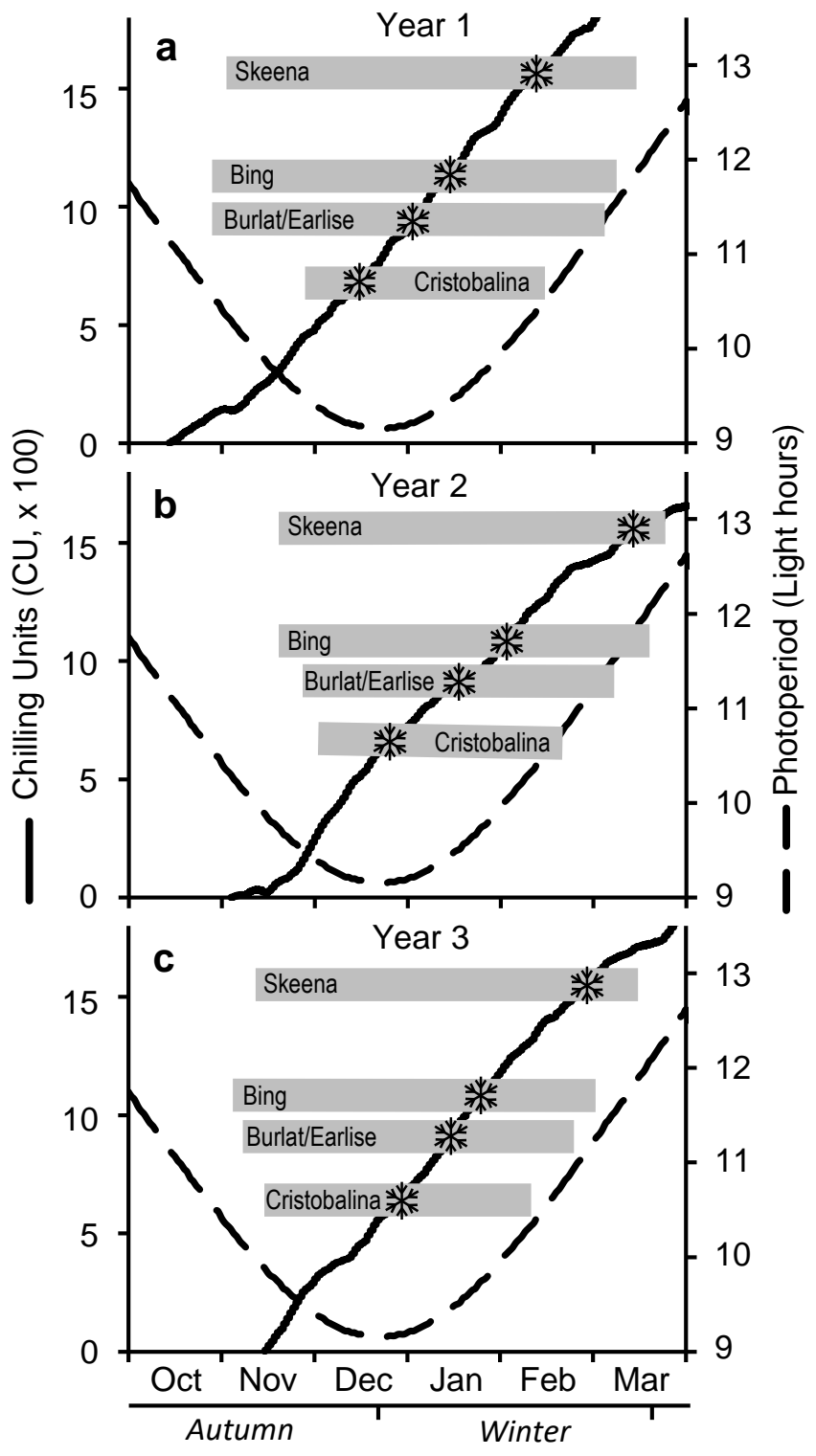


